\title{
Joaquín Sorolla, coleccionista de obras de arte, y sus estancias en Sevilla
}

\author{
Jesús Porres Benavides ${ }^{1}$ \\ Universidad Rey Juan Carlos \\ jesus.porres@urjc.es
}

Muy bien documentadas están las frecuentes estancias del pintor Joaquín Sorolla y Bastida en la ciudad de Sevilla. Para el pintor, la ciudad será, en palabras de Juan Carlos Montes, «ese río al que Narciso irá a mirarse hasta quedar atrapado en él» (Montes, 2016: 177). Sorolla mantiene con la ciudad una relación ambigua, por un lado afirmaba que «la famosa y cacareada Sevilla no es para tanto", y, por otro, sus repetidas estancias confirman esa intensa admiración que se convertirá según sus propias palabras en «una querencia necesaria».

Las temporadas en la ciudad hispalense empezarán en la Semana Santa de 1902, a la que seguirán febrero de 1908, enero de 1910 y marzo de 1914. Esta última visita la realiza acompañado de su discípulo Alfredo Carreras y, gracias a la intermediación del escultor Joaquín Bilbao, pronto encuentra un lugar para pintar en el convento de San Clemente. En el otoño de 1914 vuelve para pintar el panel Sevilla, El encierro que era uno de los catorce paneles monumentales -en total, unos 200 metros cuadrados al óleoque realizó para decorar la biblioteca de la Hispanic Society of America de Nueva York, encargados por el multimillonario Archer M. Huntington. Asimismo este año completará el cuadro El café novedades, para el también estadounidense Ryan. La navidad del 14 también la pasa en Sevilla, y a mediados de enero de 1915 está de nuevo en la ciudad con la intención de acometer el cuadro El baile y el cuadro Los nazarenos. Sevilla. La última estancia de Sorolla en la ciudad se produce en 1918.

Sorolla mantiene una intensa relación con la aristocracia sevillana y los poderes fácticos de la ciudad, que queda reflejada tanto en su correspondencia como en la amplia documentación fotográfica, mucha recogida por los periódicos de la época. Se relaciona igualmente con colegas pintores como Gustavo Bacarisas, José Villegas Cordero, Gonzalo Bilbao, Jose Jiménez Aranda y Santiago Martínez. Las vi- sitas de Sorolla dejaron una gran impronta en muchos de estos pintores, que se vieron influenciados por la novedad del estilo del maestro, muy alejado de la moda imperante en la ciudad por aquel entonces.

Ya es de sobra conocido que Sorolla, sobre todo a raíz de la construcción de su casa en Madrid (empezada en 1909 con proyecto del arquitecto Enrique María de Repullés y terminada en 1911), compró numerosas obras de arte en diferentes anticuarios de España. En Sevilla busca y compra joyas antiguas (Montes, 2016: 53), además de adquirir piezas cerámicas para esa casa en construcción. Sin duda, el Alcázar de Sevilla, al que acude con frecuencia para pintar, será una fuente de inspiración para su casa, con su gran colección de paneles cerámicos. Estas piezas le otorgaran cierto carácter andaluz a varias zonas de la casa, sobre todo a los jardines. Cuenta con objetos como cerámicas, fuentes, columnas, rejas, faroles, macetas etc., pero también para el interior «he hecho un cambalache por unas columnas doradas y talladas en madera para el estudio que son muy hermosas», quizás regalo de doña Regla Manjón para su casa. También es interesante cómo hace canje con la condesa de Lebrija, de la que, a cambio de una pintura, recibe un san Bartolomé de la escuela de Ribera.

Es interesante asimismo la afición de Sorolla a piezas escultóricas de época. Obras pétreas para la decoración del patio y obras de escultura en madera para el interior. Adquiere piezas muy destacadas tanto clásicas como medievales, renacentistas y barrocas. Algunas obras son foráneas, como la virgen regalada por el anticuario alemán Joseph Weissberger, pero algunas de las piezas más relevantes tienen un origen andaluz, como la magnífica Inmaculada atribuida a Pedro de Mena (79x69x29), adquirida en Granada al tallista Fuentes, por mediación de Don Joaquín Torrente, en 1917, y las dos esculturas que presentamos a continuación. 


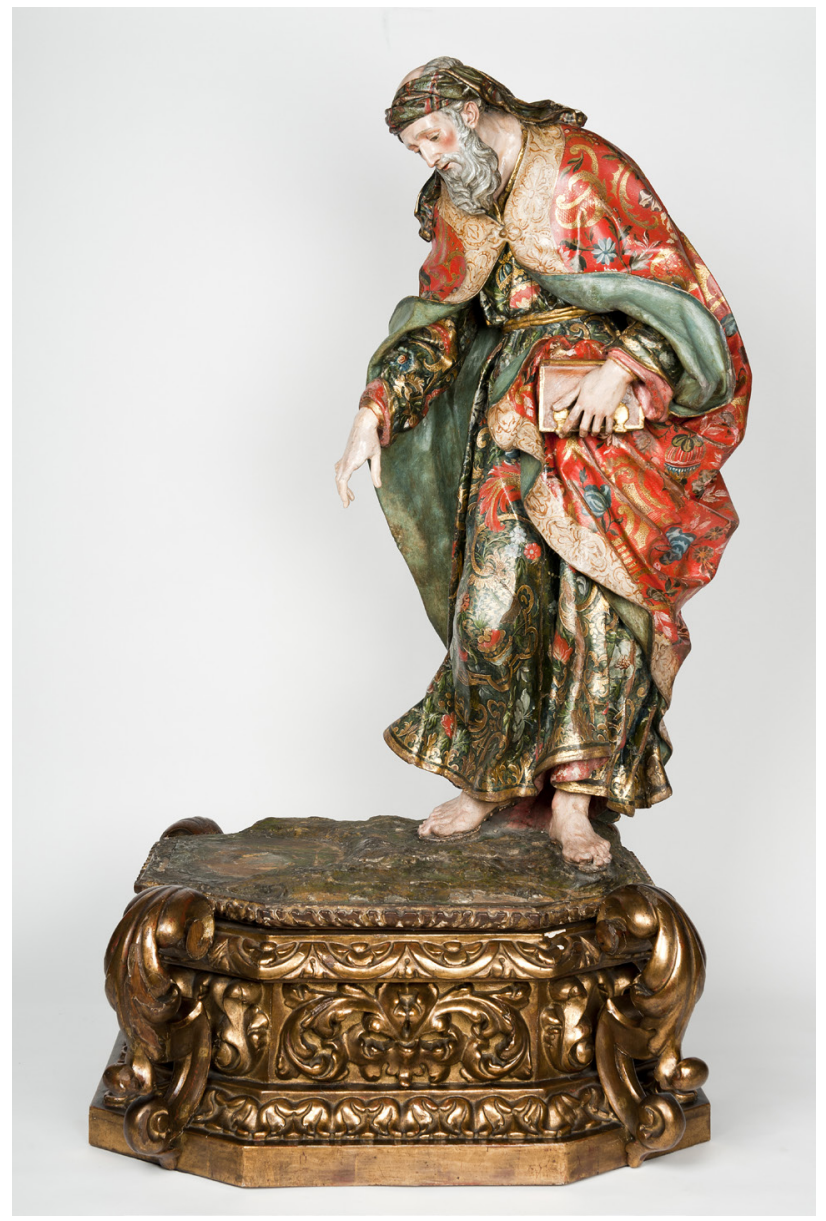

1. San Joaquín, $2^{\text {a }}$ mitad del siglo XVIII, escuela sevillana. Museo Sorolla. N. ${ }^{\circ}$ inv. 20042

Con el número 20042 del museo hay una talla de San Joaquín catalogada como Anónimo, de finales del siglo XVIII (86x60x40) [1]. Está realizada en madera policromada y estofada, y representa a San Joaquín, el padre de la Virgen María, como un hombre anciano y barbado, está de pie aunque ligeramente inclinado hacia la derecha con la mano izquierda y porta un libro a la vez que se recoge el manto, vestido con túnica y manto de pliegues muy movidos y abultados.

Formaría parte de un grupo del que falta la Virgen Niña acompañando a su padre (en su lugar hay una pieza de reflejo de cobre de hacia 1900 valenciana; agradezco a Alfonso Pleguezuelo la catalogación de esta pieza), que se inclina ofreciéndole su mano derecha (Ruiz, 1993: 28). La figura apoya sobre una peana dorada, de corte neobarroco, aunque no es

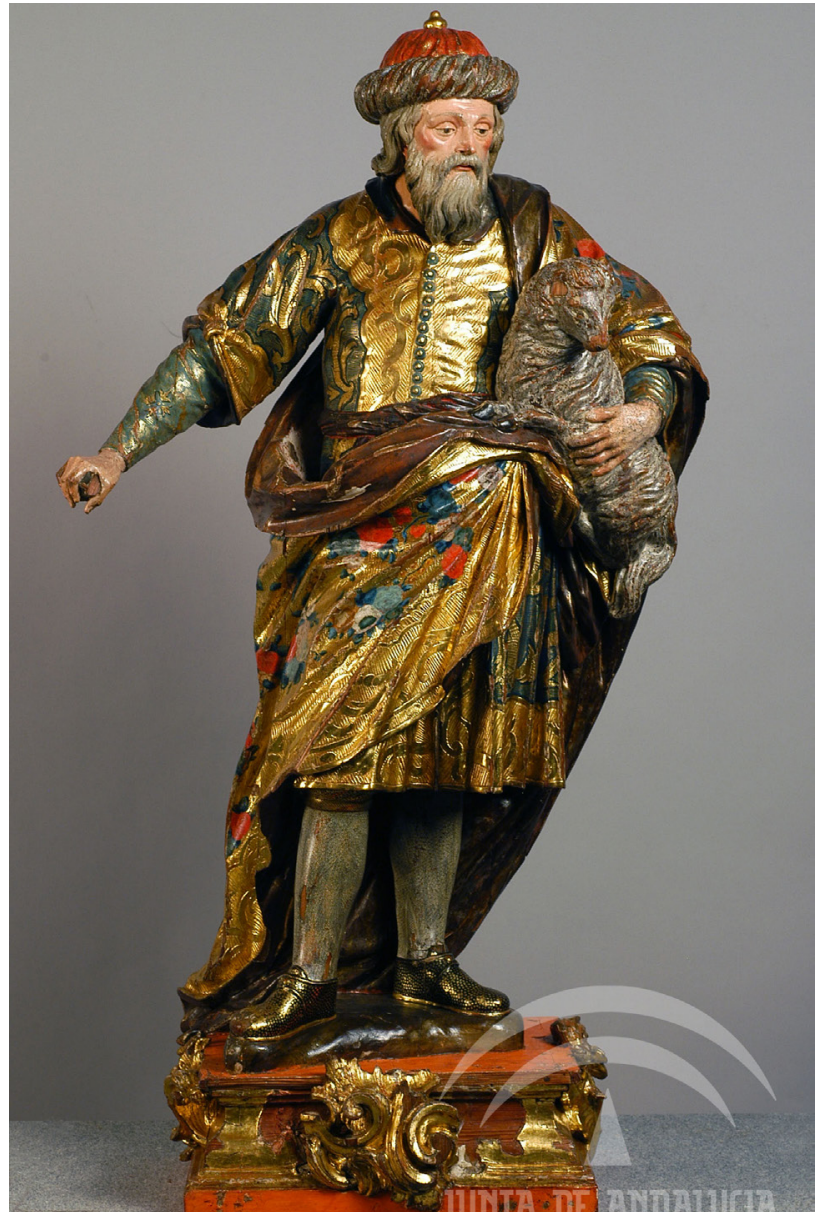

2. San Joaquín, retablo de Santa Ana del Salvador de Sevilla. Anónimo, 2. ${ }^{a}$ mitad del siglo XVIII, cortesía IAPH Sevilla

la original de la imagen. Esta peana, seguramente de factura nueva, fue adquirida por Sorolla probablemente en 1914 a un tal Antonio Roldán, comerciante de espejos, molduras y ornamentación religiosa en Sevilla ${ }^{2}$, al igual que la propia obra, por lo que intuimos que el señor Roldan se dedicaría también a la intermediación de antigüedades. Añade interés a la imagen el que se trate del santo patronímico del pintor.

Creemos que se trata de una obra sevillana de la segunda mitad del siglo XVIII ${ }^{3}$ de muy buena factura y debida posiblemente a un seguidor de Pedro Duque Cornejo por el arqueamiento de la figura, dinamismo y tratamiento de pliegues, tan ligeros y finos en zonas que parecen telas encoladas. Gran dulzura posee el rostro del anciano venerable con los ojos de cristal insertos en la mascarilla. 
Especialmente interesante es la decoración polícroma que presenta la imagen, típica de las vestimentas de las esculturas de la época. El santo lleva una túnica de color verde esgrafiada 4 sobre el oro, con flores claras y rojas acompañadas de roleos y otras formas en dorado con «picados de lustre». Lleva un gran manto cogido por un pequeño broche a la altura del pecho, de color rojo bermellón que combina elementos rocallas en dorado, con pequeños bouquets florales (motivos propios del rococó que se difunden a través de grabados ornamentales franceses y alemanes de los años 1730 y 1740), y tiene una cenefa que orla todo el manto con decoraciones sobre blanco. En la cabeza tiene un pañuelo anudado tipo hebreo pero que deja ver la calva superior. Es significativo cómo a lo largo del siglo XVIII van a desarrollarse todos estos recursos plásticos en la policromía y estofado de las imágenes (Porres, 2017), haciendo uso y a veces «abuso» de técnicas como el «picado de lustre» o cincelados, o en el acabado polícromo, y se utilizan las diferentes técnicas sobre el dorado, el plateado o el bronceado que a veces iban simuladas con corladuras o rayados, esgrafiados o estofados, decoración a pincel etc.

En la propia ciudad de Sevilla tenemos una serie de santos con esta iconografía y de esta época que se encuentran en un limbo de autoría. Quizás uno de los más interesantes sea el que se encuentra en el retablo de Santa Ana del Salvador de Sevilla [2] $]^{5}$. Esta obra del segundo tercio del XVIII ha sido objeto de las atribuciones más variopintas, desde que se trata de una obra de finales del siglo XVII a situarla como obra de autores como José Montes de Oca (que sí es, sin embargo, el autor de la Santa Ana que preside el retablo), o incluso de Cristóbal Ramos, de quien sí puede ser la imagen de San Antonio que está también en el mismo retablo. Otro ejemplo interesante y quizás atribuible a Cayetano de Acosta es el San Joaquín que se encuentra en el retablo mayor de la capilla de San Jose de los Padres Capuchinos de Sevilla [3]. Este último comparte la forma y el movimiento de brazos con el del Salvador, aunque algo diferente en el de la capilla por portar a la Virgen Niña encima en vez de una oveja. En la portada de la misma capilla de San José hay otro san Joaquín en barro cocido que guarda relación con los dos anteriores.

Con el número 20036 (en la base de la peana tiene una etiqueta seguramente con la antigua catalogación, 1029) se cataloga en la sección de escultura una pequeña

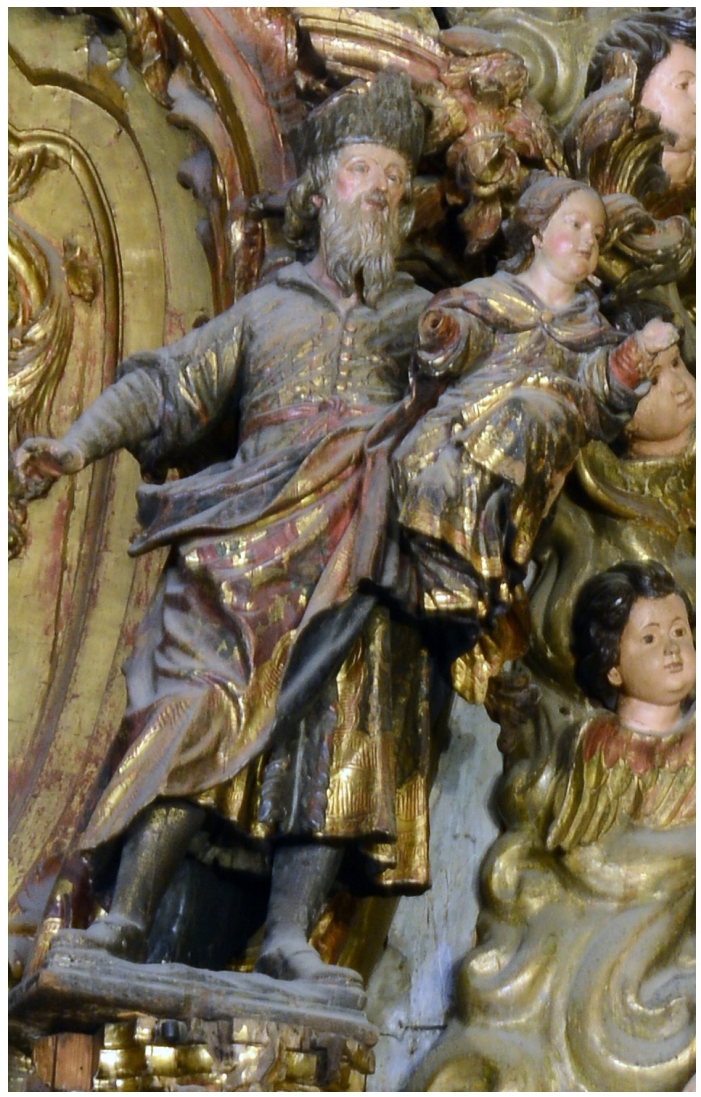

3. San Joaquín, retablo mayor capilla de San José, Sevilla. Atribuido a Cayetano de Acosta. 2. ${ }^{\text {a }}$ mitad del siglo XVIII. Imagen cedida por cortesía Juan Carlos Hernández Núñez

imagen de la Virgen Dolorosa [4], como probable obra de artista andaluz del siglo XVIII, realizada «en madera y lienzo estofados y policromados» (Ruiz, 1993: 27). Se presenta arrodillada sobre un cojín, entrelaza las manos, al tiempo que alza la mirada en actitud suplicante, muy realista y con gran fuerza dramática. El rostro está adornado con una pequeña toca blanca. Viste túnica con cinto y manto azul con cenefa dorada.

Esta obra sin duda tenemos que ponerla en relación con Cristóbal Ramos, que sintió una predilección especial por las imágenes de pequeño formato y cultivó incesantemente la temática mariana (en especial, las advocaciones del Rosario y del Carmen), contribuyendo a consagrar en el contexto hipalense la iconografía de la Dolorosa arrodillada con las manos entrelazadas, cuyo prototipo parece seguir. 


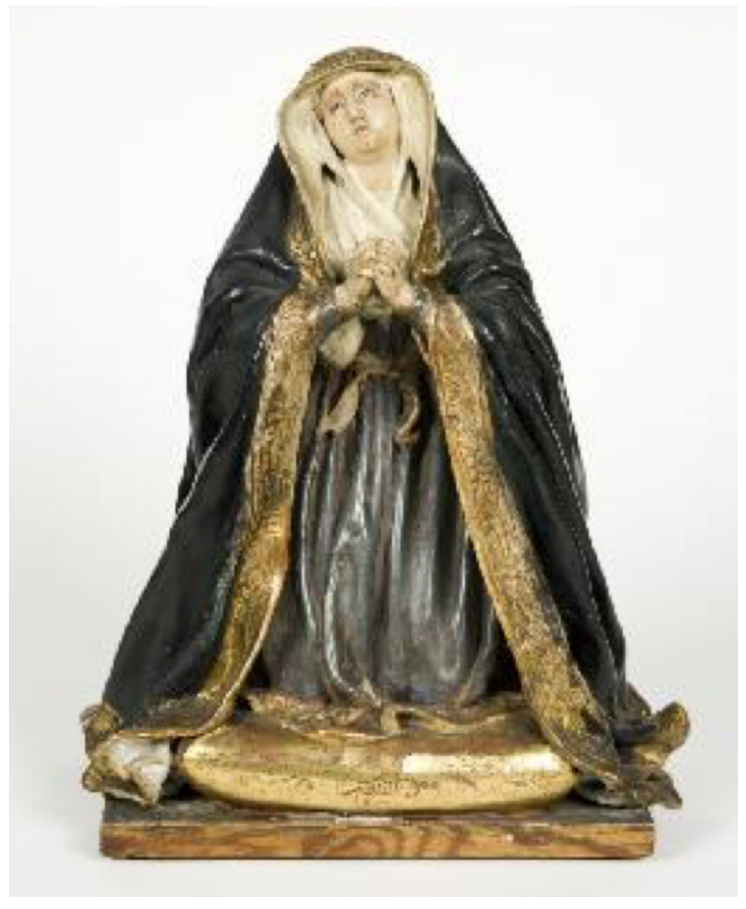

4. Dolorosa. Cristóbal Ramos. 2. ${ }^{a}$ mitad del siglo XVIII. Museo Sorolla. N. ${ }^{\circ}$ inv. 20036
La imagen del Museo Sorolla, por su pequeño tamaño (33×27x21), podría ser un modelo para enseñar a los clientes o bien una imagen devocional de pequeño formato. En cuanto a la policromía de la imagen, es de colores lisos, azul-grisáceo en la túnica y azul oscuro en el manto solamente con una cenefa con la lazada y motivos de flores en dorado que alivian esa sensación de austeridad.

Como conclusión, dice mucho de la personalidad artística de Joaquín Sorolla, quizás el pintor más cotizado en su época, no solo en España sino también en el mundo a tenor de los encargos que recibió, que supiera coleccionar piezas de época con bastante criterio de calidad. Es reseñable cómo dentro de las piezas que se conoce adquirió no sabemos de ninguna falsificación (cosa común a finales del XIX y principios del $X X$ ) y el extraordinario tesón para adquirir estas obras para la casa que él mismo diseña en Madrid y que hoy es la sede del museo. Está claro que en sus visitas a Sevilla y también al resto de Andalucía observaría la decoración de casas y palacios que después recrearía en su vivienda, así como la posibilidad de adquirir piezas de mérito como las dos que presentamos. 


\section{Notas}

1 Quiero agradecer a la conservadora Rosario López del Museo Sorolla las atenciones que ha tenido conmigo.

2 Así, en una carta del pintor Alfredo Carreras a Sorolla el 17 de Mayo de 1914 le comenta "que le dio su encargo el mismo día y este dijo que no se lo ha enviado al Sr. Joaquín para enviar al mismo tiempo la peana». Sabemos cómo una semana después el señor Roldan una caja para hacerle un «envio» posiblemente de la peana y el santo. Museo Sorolla. No de inv. CS1194.

3 Agradecemos las opiniones e informaciones que sobre esta obra me han facilitado Francisco Herrera, Alfonso Pleguezuelo y Miguel Ángel Marcos. Aunque sostenemos esta atribución, no deberíamos descartar otras escuelas como la Murciana, aunque con menos fuerza, sobre todo por la gran conexión con la decoración pictórica que tiene el manto y la túnica con decoración a punta de pincel de motivos vegetales alternados con esgrafiados o rajados sobre el oro, roleos dorados, etc., que lo acercan bastante a obras de decoración pictórica que se está realizando en esos momentos en Sevilla.

4 Una vez dorada la superficie, se podía policromar encima (generalmente aglutinados con huevo, con caseinato o incluso con calcinatos que se denominaba genéricamente temple). Una vez seca, se podían hacer labores de rayados o punzonados y retirar la pintura para conseguir efectos diversos (a veces queriendo imitar textiles o metálicos), en (Carrasson López de Letona, 2002: 193).

5 Que tuve la fortuna de intervenir en 2004. Aunque catalogado como Montes de Oca c.1714. dimensiones 114x62x42.6. El Salvador en el IAPH: Conservación de un patrimonio histórico devocional. Consejería de Cultura Instituto Andaluz del Patrimonio Histórico. Sevilla, 2007.

\section{Bibliografía}

CARRASSON LÓPEZ DE LETONA, Ana et alii (2002), «Las técnicas de dorado en los siglos XVII y XVIII en España», en W.AA., A escultura policromada religiosa dos séculos XVII e XVIII, Actas del congreso Internacional, Lisboa.

MONTES MARTíN, Juan Carlos (2016), Sorolla y Sevilla. Colección Arte Hispalense n. 107, Diputación Provincial, Sevilla.

PORRES BENAVIDES, Jesús (2017), «Intervenciones en esculturas sevillanas de madera policromada y recuperación de policromías del siglo XVIII», en W.AA., Actas del Encuentro Internacional ICOM-CC. Las encarnaciones de la escultura policromada (Siglos XI - XVIII), Madrid.

- (2017), «Joaquín Sorolla y la Semana Santa de Sevilla». Boletín de las cofradías, n. ${ }^{\circ}$ 698, abril.

RUIZ BREMÓN, Mónica (1993), Catálogo de escultura. Museo Sorolla, Dirección General de Bellas Artes y Archivos, Dirección General de los Museos Estatales, Madrid.

W.AA. (2007), El Salvador en el IAPH Conservación de un patrimonio histórico devocional, Consejería de Cultura Instituto Andaluz del Patrimonio Histórico, Sevilla. 
